\title{
Potential of the Volatile-Producing Fungus Nodulisporium sp. CF016 for the Control of Postharvest Diseases of Apple
}

\author{
Myung Soo Park, Jiye Ahn, Gyung Ja Choi, Yong Ho Choi, Kyoung Soo Jang and Jin-Cheol Kim* \\ Chemical Biotechnology Research Center, Korea Research Institute of Chemical Technology, Daejeon 305-600, Korea \\ (Received on July 30, 2010; Accepted on August 26, 2010)
}

\begin{abstract}
In vitro and in vivo mycofumigation effects of the volatileproducing fungus Nodulisporium sp. CF016 isolated from stem of Cinnamomum loureirii and the role of its volatile compounds were investigated against phytopathogenic fungi. The volatile compounds produced by Nodulisporium sp. CF016 inhibited and killed a wide range of plant and storage pathogens including to Pythium ultimum, Rhizoctonia solani, Fusarium oxysporum, Phytophthora capsici, Sclerotinia sclerotiorum, Colletotrichum coccodes, Magnaporthe oryzae, Alternaria panax, Botrytis cinerea and Penicillium expansum. Mycofumigation with wheat bran-rice hull cultures of Nodulisporium sp. CF016 showed in vivo antifungal activity against gray mold caused by $B$. cinerea and blue mold caused by $P$. expansum of apple. The most abundant volatile compound produced by Nodulisporium sp. CF016 was $\beta$-elemene followed by 1 -methyl-1,4-cyclohexadiene, $\beta$-selinene and $\alpha$-selinene. Nodulisporium sp. CF016 could be an attractive mycofumigant in controlling postharvest diseases of various fruits including apple.
\end{abstract}

Keywords : biological control agent, endophytic fungus, mycofumigation, Nodulisporium sp., postharvest disease

Postharvest losses can exceed 50\% of the harvested fruits in developing countries (Eckert and Ogawa, 1988). Postharvest losses during storage of apples are mainly caused by fungal pathogens. More than 90 species of fungi have been reported to cause decay of apples during storage (Jones and Aldwinckle, 1991). Two of the important postharvest diseases of apple worldwide are blue mold and gray mold, caused by Penicillium expansum and Botrytis cinerea, respectively.

Control of postharvest diseases still relies on the synthetic fungicides. However, several fungicides are no longer used for postharvest diseases due to toxicological risks and the appearance of fungicide resistant isolates. These reasons have increased the need for alternative control strategies.

\footnotetext{
*Corresponding author.

Phone) +82-42-860-7436, FAX) +82-42-861-4913

E-mail)kjinc@krict.re.kr
}

Biological control with microorganisms has emerged as a promising alternative with reduced environmental impact (Wilson and Wisniewski, 1994). The use of yeast or bacteria to control postharvest diseases of fruits has been reported (Janisiewicz and Korsten, 2002). The several commercial products are currently registered for the control of postharvest diseases in Europe and USA. The biofungicide such as Bio-Save 101p (Jet Harvest Solutions, Longwood, FL, USA) which contain Pseudomonas syringae as the active ingredient, respectively, have been registered in USA for the control of postharvest diseases on apples (Zhou et al., 2001). A commercial formulation of Candida sake was recently developed and registered for use on pome fruit in Spain under the name "Candifruit" (Sipcam. Inagra, Spain) (Droby et al., 2009).

Several fungi producing volatile antibiotics have been previously reported (Lee et al., 2009; Strobel et al., 2001; Stinson et al., 2003a and 2003b). Muscodor albus isolated from limbs of Cinnamomum zeylanicum is a mycofumigant that inhibits and kills fungi and bacteria in enclosed areas by producing a mixture of volatile compounds (Strobel et al., 2001). The natural mycofumigant (AgraQuest, Inc., Davis, CA, USA) by M. albus strain QST 20799 has been registered in USA for the control of plant pathogens. In addition, a mixture of volatile compounds of M. albus and $M$. roseus effectively inhibited soilborne diseases caused by Pythium ultimum, Aphanomyces cochlioides, Rhizoctonia solani and Verticillium dahlia (Stinson et al., 2003a). Gliocladium sp. effectively killed $P$. ultimum and $V$. dahlia by producing a mixture of volatile compounds (Stinson et al., 2003b). The most abundant antifungal volatiles of $M$. albus and Gliocladium sp. were 1-butanol and 3-methylacetate, and annulene, respectively (Strobel et al., 2001; Stinson et al., 2003b). Oxyporus latemarginatus EF069 isolated from healthy tissue of red pepper showed fumigation activity against postharvest apple decay and Rhizoctonia root rot on moth orchid caused by $B$. cinerea and $R$. solani, respectively, through production of 5-Pentyl-2furaldehyde (Lee et al., 2009). The antifungal volatileproducing fungi are expected to be useful as potential sources of new bioactive compounds and as biocontrol agents by mycofumigation against postharvest diseases. 
In this study, the antifungal volatile-producing endophytic fungus Nodulisporium sp. CF016 was selected as a potential biological agent from various fungi isolated from leaf and stem tissues of Lauraceae trees. The mycofumigation effects of Nodulisporium sp. CF016 were examined against plant pathogens in vitro and in vivo. The volatile compounds were identified by gas chromatograph-mass spectrometer (GC-MS).

\section{Materials and Methods}

Isolation of endophytic fungi. Samples of leaf and stem tissues from Lauraceae trees were collected from regions of Jeju Island, Korea. The samples were washed in running tap water and cut into small pieces of approximately $4 \mathrm{~mm}^{2}$. Tissue pieces were washed in $0.1 \%$ Tween 20 for $10 \mathrm{~s}$, surface-sterilized in $2 \%$ sodium hypochlorite for $10 \mathrm{~s}$, and then washed in sterile distilled water. The surface-sterilized tissue pieces were placed on cornmeal malt extract agar medium [17.0 g cornmeal agar (Becton, Dickinson and Company, MA, USA), $20.0 \mathrm{~g}$ malt extract agar (Becton, Dickinson and Company), and $2.0 \mathrm{~g}$ yeast extract (Becton, Dickinson and Company) per liter, to which $50 \mathrm{mg} / \mathrm{l} \mathrm{chlor-}$ amphenicol was added (Sigma Chemical Co., St. Louis, USA)] (Suto et al., 2002) and incubated at $25^{\circ} \mathrm{C}$. The fungi growing out of the tissue pieces were transferred to potato dextrose agar (PDA; Becton, Dickinson and Company). A total of 38 endophytic fungi were isolated from Lauraceae trees (Table 1). These isolates were stored in sterile distilled water at $4{ }^{\circ} \mathrm{C}$ and $20 \%$ glycerol at $-80^{\circ} \mathrm{C}$.

Screening for fumigation activity of endophytic fingi. All of the endophytic fungi isolated from Lauraceae trees were tested by mycofumigation assay (Strobel et al., 2001; Lee et al., 2009) to select potential biological control agents for postharvest diseases. For fumigation assay for postharvest apple decay caused by $B$. cinerea, PDA medium was poured into half-plate separated Petri plates $(90 \times 15$ $\mathrm{mm}$; SPL Life Science, Korea). Each endophytic fungus was inoculated on one side of the plate and incubated for 3 days at $25^{\circ} \mathrm{C}$. Subsequently, an agar plug of $B$. cinerea was placed on other side of plate and the plates were sealed with Parafilm. Control experments were conducted in which $B$. cinerea was subjected to the same procedures minus endophytic fungi on the test side of the petri plates. The fumigation assay plates were incubated for 3 days at $25^{\circ} \mathrm{C}$. Then the radii of fungal mycelia were measured and compared with that of control. Each experiment was performed in three replications.

Identification of CF016. Isolate CF016 obtained from stem tissue of Cinnamomum loureirii Ness was identified
Table 1. In vitro fumigation activity of endophytic fungi isolated from Lauraceae trees against Botrytis cinerea

\begin{tabular}{|c|c|c|c|}
\hline $\begin{array}{l}\text { Fungus } \\
\text { isolate }\end{array}$ & Plant origin & $\begin{array}{c}\text { Part } \\
\text { of plant }\end{array}$ & $\begin{array}{l}\text { Fumigation } \\
\text { activity }^{\mathrm{a}}\end{array}$ \\
\hline CF001 & Cinnamomum loureirii & Leaf & - \\
\hline CF002 & Litsea japonica & Stem & - \\
\hline CF003 & Litsea japonica & Stem & - \\
\hline CF004 & Machilus thunbergi & Stem & - \\
\hline CF005 & Machilus thunbergi & Stem & - \\
\hline CF006 & Neolitsea sericea & Stem & - \\
\hline CF007 & Neolitsea sericea & Leaf & - \\
\hline CF008 & Neolitsea sericea & Stem & - \\
\hline CF009 & Neolitsea sericea & Stem & - \\
\hline CF010 & Cinnamomum japonicum & Stem & - \\
\hline CF011 & Cinnamoтum japonicum & Stem & - \\
\hline $\mathrm{CF} 012$ & Cinnamoтum japonicum & Stem & - \\
\hline CF013 & Neolitsea aciculata & Leaf & - \\
\hline CF014 & Cinnamomum loureirii & Leaf & - \\
\hline CF015 & Litsea japonica & Stem & - \\
\hline CF016 & Cinnamomum loureirii & Stem & + \\
\hline CF017 & Cinnamomum camphora & Stem & - \\
\hline CF018 & Neolitsea sericea & Stem & - \\
\hline CF019 & Cinnamomum japonicum & Leaf & - \\
\hline CF020 & Cinnamomum japonicum & Leaf & - \\
\hline CF021 & Cinnamomum camphora & Stem & - \\
\hline $\mathrm{CF} 022$ & Cinnamomum camphora & Stem & - \\
\hline $\mathrm{CF} 023$ & Neolitsea aciculata & Leaf & - \\
\hline CF024 & Cinnamomum japonicum & Leaf & - \\
\hline $\mathrm{CF} 025$ & Cinnamomum camphora & Stem & - \\
\hline $\mathrm{CF} 026$ & Litsea japonica & Leaf & - \\
\hline CF027 & Neolitsea aciculata & Stem & - \\
\hline CF028 & Machilus thunbergi & Leaf & - \\
\hline CF029 & Neolitsea sericea & Stem & - \\
\hline CF030 & Neolitsea aciculata & Stem & - \\
\hline CF031 & Neolitsea sericea & Leaf & - \\
\hline CF032 & Litsea japonica & Stem & - \\
\hline CF033 & Cinnamomum loureirii & Leaf & - \\
\hline CF034 & Neolitsea aciculata & Stem & - \\
\hline CF035 & Litsea japonica & Stem & - \\
\hline CF036 & Cinnamomum camphora & Leaf & - \\
\hline CF037 & Cinnamomum camphora & Leaf & - \\
\hline CF038 & Cinnamomum camphora & Leaf & - \\
\hline
\end{tabular}

${ }^{a}$ Fumigation activity was determined by inhibition of mycelial growth of $B$. cinerea; +, inhibition activity: -, no inhibition

based on morphological characteristics and sequence analyses of internal transcribed spacer (ITS) regions of rRNA genes. Colony and morphological characteristics were examined on culture grown in darkness at $25^{\circ} \mathrm{C}$ for 5 days on PDA.

The isolation of genomic DNA and PCR amplification of 
the ITS regions of rRNA gene were performed using previously described methods (Park et al., 2005). The PCR fragments were purified using Wizard PCR prep Kits (Promega, WI, USA) and directly sequenced using a BigDye terminator cycle sequencing kit (Applied Biosystems, CA, USA), according to the manufacturer's instruction. The same primer sets for the PCR amplification were used to sequence both DNA strands. The gel electrophoresis and data collection were performed on an ABI Prism 310 Genetic Analyzer (Applied Biosystems).

The sequences were compared with ITS regions of rRNA gene sequences available in the Genbank database by the BLAST search. Sequences generated from materials in this study and retrieved from GenBank were initially aligned using the program CLUSTAL X (Thompson et al., 1997), and then the alignment was refined manually using the PHYDIT program version 3.0 (Chun 1995; available at http://plaza.snu.ac.kr/jchun/phydit). Ambiguously aligned regions were excluded from the subsequent analyses. A neighbor-joining tree was reconstructed with Kimura's 2parameter distance model (Kimura, 1980) using the PHYLIP 3.57c package (Felsenstein, 1985). The bootstrap analysis using 1,000 replications was performed to assess the relative stability of the branches.

In vitro assay for fumigation activity of CF016. For fumigation assay for plant pathogen, PDA medium was poured into half-plate separated Petri plates. A total of 10 plant pathogens were used in this study; Pythium ultimum, Rhizoctonia solani, Fusarium oxysporum, Phytophthora capsici, Sclerotinia sclerotiorum, Colletotrichum coccodes, Magnaporthe oryzae, Alternaria panax, Botrytis cinerea and Penicillium expansum. These plant pathogens were isolated from infected plant materials in our laboratory, except $P$. expansum, which was kindly provided by Dr. S.H. $\mathrm{Yu}$, Chungnam National University. CF016 was inoculated on one side of half-plate separated Petri plates and incubated for 5 days at $25^{\circ} \mathrm{C}$. An agar plug of a plant pathogen was placed on the other side of the plate and the plates were sealed with Parafilm. Control experments were conducted in which $B$. cinerea was subjected to the same procedures minus endophytic fungi on the test side of the petri plates. The fumigation assay plates were incubated for 3 days at $25^{\circ} \mathrm{C}$ and then the radii of fungal mycelia were measured and compared with that of control. Each experiment was performed in three replications. Agar plugs of a plant pathogen that did not grow were transferred to fresh PDA to assess their viability. The experiments were repeated two times.

In vivo assay for fumigation activity of CF016. Each fruit was wounded with $8 \mathrm{~mm}$ diameter cork borer, and then 8 mm diameter mycelial plugs of $P$. expansum and $B$. cinerea were inoculated. Four-inoculated fruits were arranged in a moistened $6.5 l$ container as a replicate of each treatment. To produce wheat bran-rice hull culture of Nodulisporium sp. CF016, 70g of wheat bran and $10 \mathrm{~g}$ of rice hull were placed in Erlenmeyer flasks (1 1) with $100 \mathrm{ml}$ of distilled water and autoclaved twice for $20 \mathrm{~min}$ at $121^{\circ} \mathrm{C}$ twice with a $24 \mathrm{~h}$ interval. The solid medium was inoculated with mycelia plugs from 5-day-old PDA plate of the fungus. One week-old culture of Nodulisporium sp. CF016 on wheat bran-rice hull was used in mycofumigation assay. Wheat bran-rice hull culture of Nodulisporium sp. CF016 was applied at $12.5 \mathrm{~g}, 25.0 \mathrm{~g}$ and $50.0 \mathrm{~g}$ in a plastic cup for each container immediately after inoculation and the containers were closed. The containers were sealed and stored at $20^{\circ} \mathrm{C}$ (B. cinerea) and $25^{\circ} \mathrm{C}$ (P. expansum) in dark. After 7 days, the radii of rotted symptoms were measured from edge of the agar inoculum plug on the fruit surface. The experiment was conducted twice with two replicates per treatment and the four values for each treatment and control percentages were calculated.

Analysis of volatile compounds produced by CF016. The gas in the air space above cultures of CF016 grown on $20 \mathrm{ml}$ of PDA in $100 \mathrm{ml}$ culture glass bottle $(61 \times 77 \mathrm{~mm}$; KisanBiotech, Seoul, Korea) was analyzed by GC-MS (Shimadzu GC-MS QP5050, Shimadzu co., Kyoto, Japan). A solid phase micro-extraction syringe (Supelco Inc., PA, USA) was used to trap fungal volatiles. The syringe tip was inserted through a hole in the screw-caps of CF016 culture bottles and exposed to the gas phase for $1 \mathrm{~h}$. The syringe was then inserted into the splitless injection port of the GCMS. A capillary column SPB-5 (30 $\mathrm{m} \times 0.25 \mathrm{~mm}$ i.d., 0.25 $\mu \mathrm{m}$ film thickness; Supelco Inc.) was used. The initial temperature of the column was held at $30^{\circ} \mathrm{C}$ for $2 \mathrm{~min}$, programmed at $5^{\circ} \mathrm{C} \mathrm{min}{ }^{-1}$ to $220^{\circ} \mathrm{C}$. The injection port and interface were set at $240^{\circ} \mathrm{C}$ and $200^{\circ} \mathrm{C}$, respectively. Helium was the carrier gas at a flow rate of $2.2 \mathrm{ml} \mathrm{min}^{-1}$.

Statistical analysis. Analysis of variance was performed on the PROC GLM procedure (SAS institute, Cary, NC). If $P>F$ was less than 0.01 , means were separated with Duncan's multiple range test at the $P=0.05$ level.

\section{Results}

Isolation and identification of endophytic fungi producing antifungal volatile compounds. Among the 38 endophytic fungi isolated from Lauraceae trees, one fungus, designated CF016, which was isolated from stem of Cinnamomum loureirii showed antifungal activity against $B$. cinerea by fumigation (Table 1 ). The colony of isolate 


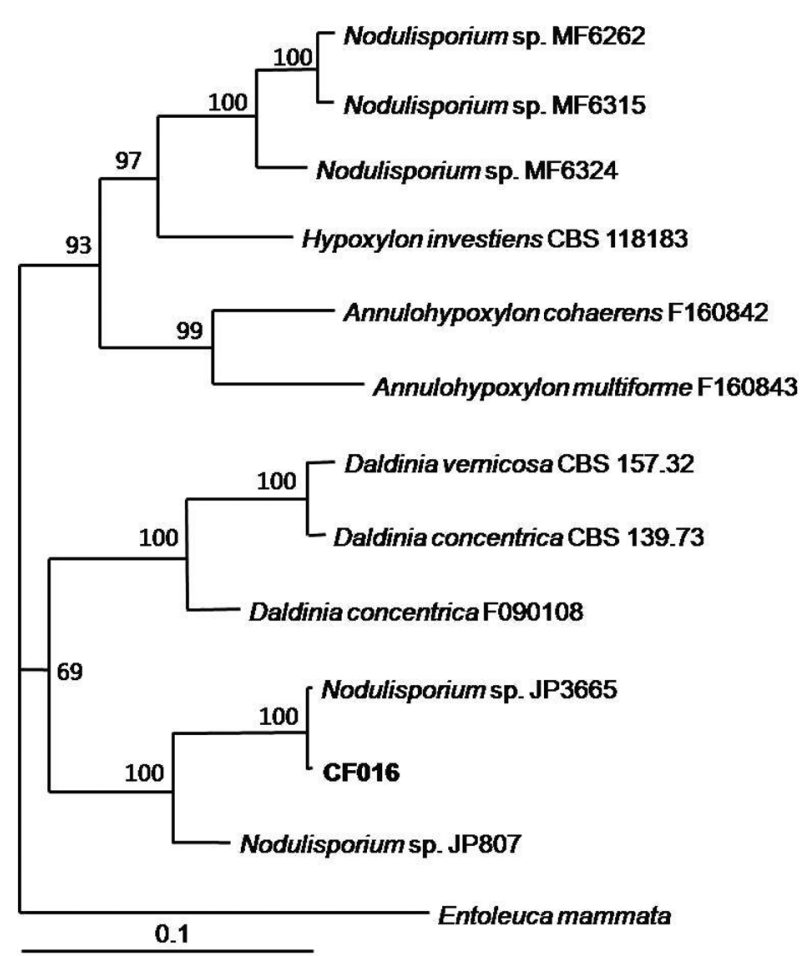

Fig. 1. Neighbor-joining tree based on ITS sequences showing relationships among endophytic Nodulisporium sp. CF016 and other xylariaceous fungi. The values above each branch indicate the percentage levels of bootstrap support $(>50 \%)$ for the branch point based on 1000 resamplings. The bar represents 0.1 substitutions per nucleotide position.

CF016 rapidly grew on PDA and was pale smoke gray. The reverse was pale brown at first, turning to blackish brown with age. Conidia were smooth, rounded at the apex, and ellipsoidal to obovoid.

Based on the sequence analyses of ITS regions of rRNA gene, Nodulisporium species were divided into two groups; one group produces nodulisporic acid and the other group does not. Isolate CF016 formed a monophyletic group with isolates of Nodulisporium sp. which does not produce nodulisporic acid (Fig. 1). Isolate CF016 shared a 99\% sequence similarity with Nodulisporium sp. JP3665 isolated from woody plant tissue. Thus, based on these results, isolate CF016 was identified as Nodulisporium sp. CF016.

In vitro assay for fumigation activity of Nodulisporium sp. CF016. Nodulisporium sp. CF016 inhibited the growth of all of the plant pathogenic fungi tested in this study (Table 2). R. solani, S. sclerotiorum, C. coccodes, and B. cinerea were completely dead 3 days after exposure to Nodulisporium sp. CF016. Mycelial growth of A. panax and $P$. expansum was inhibited by $87 \%$ and $80 \%$ compared with the untreated control, respectively. P. ultimum, F. oxy-
Table 2. Inhibition of mycelial growth of various phytopahotgenic fungi by volatile compounds produced by Nodulisporium sp. CF016.

\begin{tabular}{lrl}
\hline \hline \multicolumn{1}{c}{ Phytopathogen } & $\begin{array}{c}\text { Inhibition rate } \\
( \pm \mathrm{SD})(\%)^{\mathrm{a}}\end{array}$ & Viability $^{\mathrm{b}}$ \\
\hline Pythium ultimum & $32( \pm 7.1)$ & Fungistatic \\
Rhizoctonia solani & $100( \pm 0.0)$ & Fungicidal \\
Fusarium oxysporum & $46( \pm 10)$ & Fungistatic \\
Phytophthora capsici & $54( \pm 11)$ & Fungistatic \\
Sclerotinia sclerotiorum & $100( \pm 0.0)$ & Fungicidal \\
Colletotrichum coccodes & $100( \pm 0.0)$ & Fungicidal \\
Magnaporthe oryzae & $43( \pm 9.6)$ & Fungistatic \\
Alternaria panax & $87( \pm 12)$ & Fungistatic \\
Botrytis cinerea & $100( \pm 0.0)$ & Fungicidal \\
Penicillium expansum & $80( \pm 2,9)$ & Fungistatic \\
\hline
\end{tabular}

${ }^{a}$ The inhibition rate was calculated as percentage growth inbition 3 days after exposure to volatile compounds of Nodulisporium sp. CF016 as compared to an untreated control. Each value represents the mean of two times with three replications ( \pm the standard deviation).

${ }^{\mathrm{b}}$ Viability of the test phytopahotgenic fungi was determined 3 days after exposure to volatile compounds of Nodulisporium sp. CF016 and transfer to a fresh PDA plate.

sporum, P. capsici, and M. oryzae were relatively resistant to the volatile compounds produced by Nodulisporium sp. CF016.

In vivo assay for fumigation activity of Nodulisporium sp. CF016. The apple fruits inoculated with $B$. cinerea and $P$. expansum were fumigated with wheat bran-rice hull culture of Nodulisporium sp. CF016. The results clearly displayed that the volatile compounds produced by Nodulisporium sp. CF016 suppressed lesion development of gray mold and blue mold on apple fruits. The effect on controlling blue mold and gray mold on apple fruits depended on fumigant dose. The effect was dose-dependent; treatment with $50.0 \mathrm{~g}$ of the solid culture of Nodulisporium sp. CF016 gave the best control. Fumigation with CF016 suppressed gray mold lesion development by $35 \%, 68 \%$ and $88 \%$ at $12.5,25.0$ and $50.0 \mathrm{~g}$ for 6.5 container, respectively (Fig. 2). For blue mold, the control efficacies were $38 \%$, $58 \%$ and $76 \%$ at $12.5,25.0$ and $50.0 \mathrm{~g}$ for $6.5 l$ container, respectively (Fig. 3).

Analysis of volatile compounds of CF016. Nodulisporium sp. CF016 was subjected to analysis of the head-space volatiles in a 5-day-old culture using GC-MS. The identification of volatile organic compounds has only been tentatively identified on the basis of the The National Institute of Standards and Technology (NIST) database information. The headspace analysis of Nodulisporium sp. 

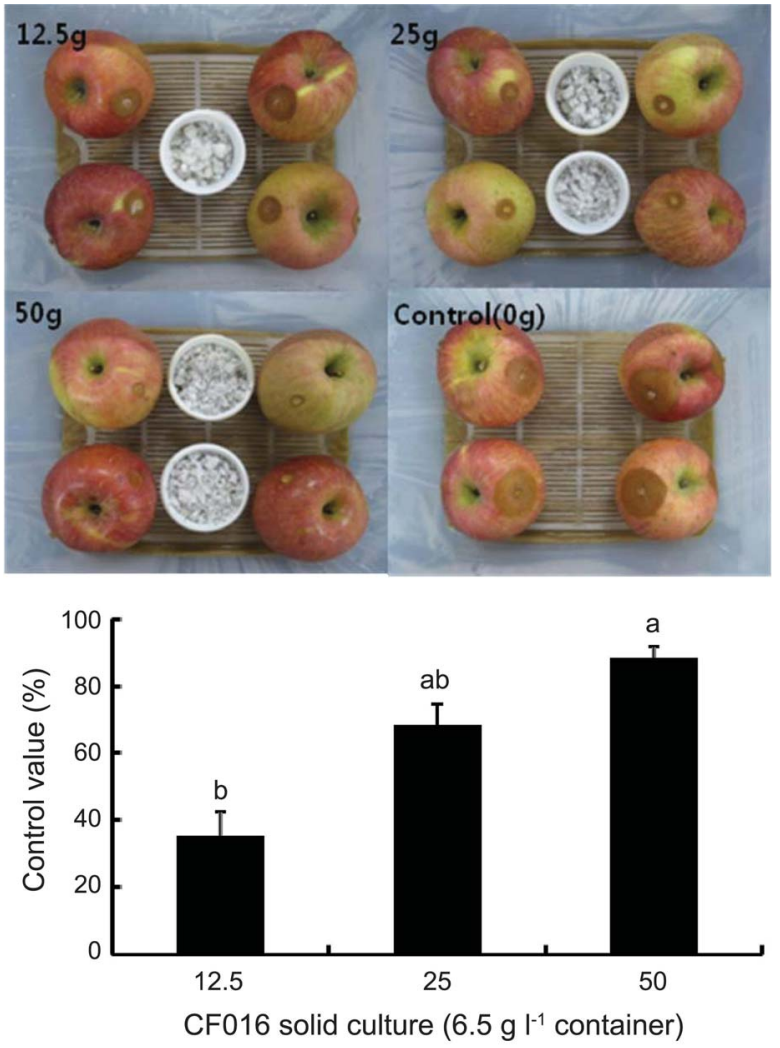

Fig. 2. In vivo antifungal activity of mycofumigation with Nodulisporium sp. CF016 against gray mold caused by Botrytis cinerea. Gray mold development (above) and control value (below) on apple as applied at dosages of $12.5 \mathrm{~g}, 25.0 \mathrm{~g}, 50.0 \mathrm{~g}$, and $0 \mathrm{~g}$ of solid culture of Nodulisporium sp. 7 days after incubation at $20^{\circ} \mathrm{C}$ in dark. Control value $(\%)=100 \times$ rotted symptom radius of untreated fruit - rotted symptom radius of treated fruit $\} \div$ rotted symptom radius of untreated fruit. The lower-case letters indicate values that are not significantly different $(P=0.05)$ to other values with the same letter in column, according to Duncan's multiple range test.

CF016 culture displayed four major volatile compounds and three minor compounds. The most abundant compound, based on the total area of the GC-MS analysis, was $\beta$-elemene $(33.0 \%)$ followed by 1-methyl-1,4-cyclohexadiene (32.2\%), $\beta$-selinene (14.5\%) and $\alpha$-selinene (9.6\%) (Table 3). The four major components accounted for $89.3 \%$ of the total volatile compounds produced. 5,5-dimethyl-1,3cyclopentadiene, 2-methyl-5,6-dihydro-2H-pyran, and cyclohexane were detected as minor compounds.

\section{Discussion}

The antifungal volatile-producing isolate CF016 obtained from stems of $C$. loureiroi was selected as potential biological control agent for postharvest disease of apple fruit. Based on the sequence analysis of ITS regions of rRNA
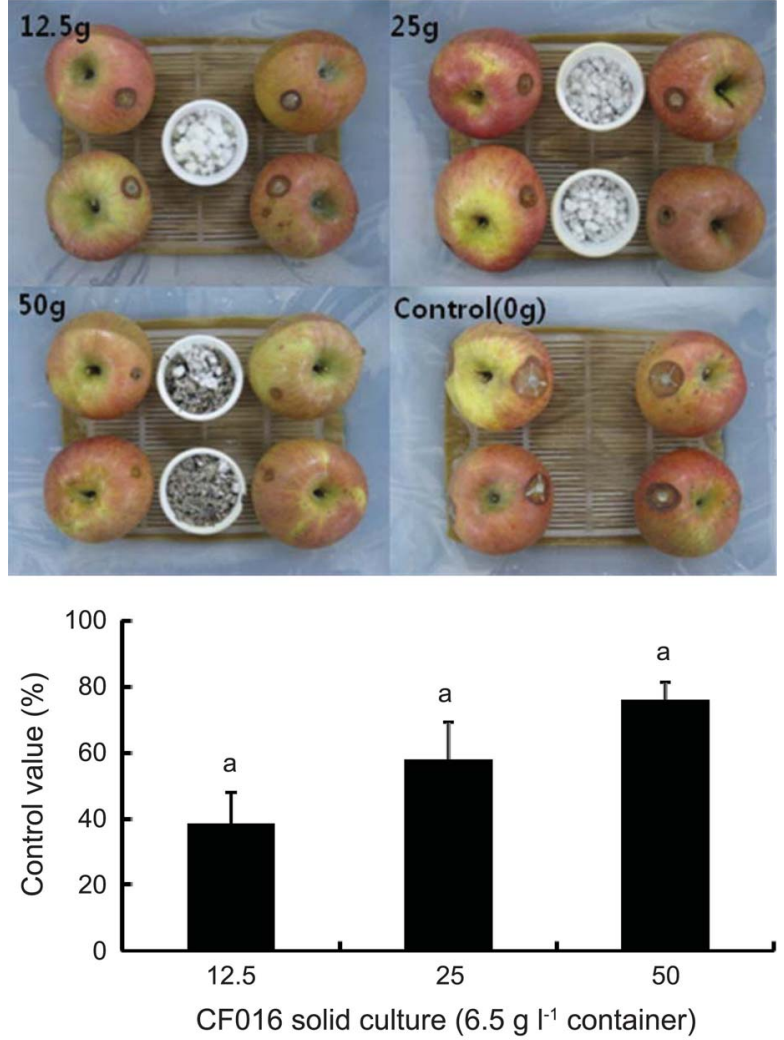

Fig. 3. In vivo antifungal activity of mycofumigation with Nodulisporium sp. CF016 against gray mold caused by Penicillium expansum. Blue mold development (above) and control value (below) on apple as applied at three dosages of $12.5 \mathrm{~g}, 25.0$ $\mathrm{g}, 50.0 \mathrm{~g}$, and $0 \mathrm{~g}$ of solid culture of Nodulisporium sp. 7 days after incubation at $25^{\circ} \mathrm{C}$ in dark. Control value $(\%)=100 \times$ \{rotted symptom radius of untreated fruits - rotted symptom radius of treated fruits $\} \div$ rotted symptom radius of untreated fruits. The lower-case letters indicate values that are not significantly different $(P=0.05)$ to other values with the same letter in column, according to Duncan's multiple range test.

gene, CF016 was grouped with Nodulisporium sp. not producing nodulisporic acid. The sequence of ITS regions of rRNA gene of CF016 was 99\% similar to Nodulisporium sp. JP3665 isolated from woody plant tissue. Thus, it is reasonable to identify the isolate CF016 as Nodulisporium sp.

The genus Nodulisporium Preuss was reported as an anamorph of at least 10 genera (e.g., Hypoxylon Bull, Xylaria Hill: Schrank, Camillea Fr., and Biscogniauxia Kuntze) of Xylariaceae (Whalley 1996). These teleomorph genera are distributed worldwide and known to be plant pathogen, wood decay or endophytic fungi. Endophytic Nodulisporium sp. was found to produce nodulisporic acid, an indole terpene, which exhibited insecticidal activity for first instars of Lucilia sericata (Ostlind et al., 1997). Recently, seven new compounds and ten known compounds 
Table 3. GC-MS analysis of the volatile compounds produced by Nodulisporium sp. CF016.

\begin{tabular}{crl}
\hline \hline $\begin{array}{c}\text { Retention time } \\
(\mathrm{min})\end{array}$ & $\begin{array}{c}\text { Total area } \\
(\%)\end{array}$ & \multicolumn{1}{c}{ Possible compound } \\
\hline 4.5 & 1.8 & 5,5-Dimethyl-1,3-cyclopentadiene \\
5.9 & 32.2 & 1-Methyl-1,4-cyclohexadiene \\
14.2 & 1.1 & 2-Methyl-5,6-dihydro-2H-pyran \\
22.6 & 2.7 & Cyclohexane \\
22.9 & 33.0 & $\beta$-Elemene \\
24.6 & 14.5 & $\beta$-Selinene \\
24.8 & 9.6 & $\alpha$-Selinene \\
\hline
\end{tabular}

from a culture extract of endophytic Nodulisporium sp. isolated from Juniperus cedre exhibited herbicidal, antifungal and/or antibacterial activity (Dai et al., 2006). In particularly, 1-(2,6-dihydroxyphenyl) butan-1-one strongly inhibited Bacillus megaterium, Septoria tritici and Chlorella fusca in an agar diffusion test.

While endophytic fungi have been known to produce volatile compounds, the production of volatile antibiotics produced by endophytic fungi has been little investigated. Muscodor albus is known to make volatile compounds having the power to inhibit and kill other fungi and bacteria (Strobel et al., 2001). The most effective class of antibiotic compounds was esters, of which isoamyl acetate was the most biologically active. $M$. albus has been developed by AgraQuest, Inc. (Davis, CA) for control of plant pathogens, insects and nematodes. Recently, AgraQuest, Inc. received Environmental Protection Agency (EPA) approval of natural fumigant based on $M$. albus strain QST 20799. In addition, Gliocladium sp. and O. latemarginatus EF069 were found to volatile antibiotics (Stinson et al., 2003; Lee et al., 2009). The primary volatile compound produced by Gliocladium sp. is annulene, a compound previously not discovered as natural product. Gliocladium sp. effectively killed $P$. ultimum and $V$. dahlia by producing a mixture of volatile compounds (Stinson et al., 2003). O. latemarginatus EF069 effectively inhibited in vitro and in vivo the growth of fungal plant pathogens by producing 5-pentyl-2-furaldehyde (Lee et al., 2009).

In vitro assay for fumigation activity, inhibitory activity of the volatile compounds produced by Nodulisporium sp. CF016 was different according to plant pathogen. The volatile compounds killed $S$. sclerotiorum, C. coccodes, and B. cinerea, while other plant pathogens tested in this study were inhibited. Mycofumigation with Nodulisporium sp. CF016 was effective in controlling blue mold and gray mold of apples caused by $P$. expansum and B. cinerea, respectively.

Nodulisporium sp. CF016 growing on PDA was found to produce a number of volatile compounds. Nodulisporium sp. CF016 growing on PDA produced more than seven volatile compounds including $\beta$-elemene, 1-methyl-1,4cyclohexadiene, $\beta$-selinene and $\alpha$-selinene in the headspace. $\beta$-Elemene is a volatile terpene found in botanicals such as celery, mint, and in many herbs used in traditional medicine. The extract containing $\beta$-elemene isolated from $R h i$ zoma zedoariae, a type of ginger plant, has been reported to relieve pain, decrease the side effects of chemotherapy, and increase the quality of life in cancer patients. In vitro studies show possible anti-proliferative effects through cell-cycle arrest and induction of apoptosis (Li et al., 2005; Wang et al., 2005; Yao et al., 2008). Malele et al. (2003) reported that essential oil of Hyptis suaveolens containing $\beta$-elemene $(10.4 \%)$ exhibited significant antimicrobial activity against Mucor sp. (Malele et al., 2003). $\beta$-Selinene was detected as a minor component in the essential oils from needles of Pinus koraiensis, aerial parts of Artemisia absinthium and aerial parts of Hypericum heterophyllum showing antifungal activities against various plant pathogens (Cakir et al., 2003; Hong et al., 2004; Kordali et al., 2005). $\alpha$ Silinene was also found as a minor component in essential oils from aerial parts of $A$. santonicum (Kordali et al., 2005). 1-Methyl-1,4-cyclohexadiene as a volatile compound is structurally similar to benzene and toluene (Raines et al., 2004), but biological activity of 1-methyl-1,4-cyclohexadiene previously was not reported. The volatile compounds of Nodulisporium sp. CF016 are totally different from those of M. albus and Gliocladium sp. To our knowledge, this is the first report of a Nodulisporium isolate producing antifungal volatiles. All of the four major compounds produced by CF016 were first found in fungi.

In this study, Nodulisporium sp. CF016 killed or inhibited mycelial growth of various fungal plant pathogens and effectively suppressed the development of postharvest diseases of apple without direct contact with the apples to be treated. Nodulisporium sp. CF016 producing volatile antibiotics may be more useful for controlling postharvest disease during storage and shipment systems than current biological or chemical fungicides requiring spraying or drenching as application methods. Nodulisporium sp. CF016 has the potential to replace the use of chemical fungicides. Potential applications of CF016 against soil borne plant pathogen in vivo and in the field are currently being investigated.

\section{Acknowledgements}

This research was supported by a grant (20070301034004) from BioGreen 21 Program, Rural Development Administration, Korea. 


\section{References}

Cakir, A., Kordali, S., Zengin, H., Izumi, S. and Hirata, T. 2003. Composition and antifungal activity of essential oils isolated from Hypericum hyssopifolium and Hypericum heterophyllum. Flavour Fragr. J. 19:62-68.

Chun, J. 1995. Computer-assisted classification and identification of actinomycetes. Ph. D. thesis. University of Newcastle, Newcastle upon Tyne, UK.

Dai, J., Krohn, K., Flörke, U., Draeger, S., Schulz, B., Kiss-Szikszai, A., Antus, S., Kurtán, T. and van Ree, T. 2006. Metabolites from the endophytic fungus Nodulisporium sp. from Juniperus cedre. Eur. J. Org. Chem. 15:3498-3506.

Dennis, C. and Webster, J. 1971. Antagonstics properties of species groups of Trichoderma. Part II. Production of volatile antibiotics. Trans. Br. Mycol. Soc. 57:41-48.

Douglas E. Raines, D. E., Robert, F. G., Claycomb, J. and Stevens, R. J. 2004. The $N$-methyl-D-aspartate receptor inhibitory potencies of aromatic inhaled drugs of abuse: evidence for modulation by cation- $\pi$ interactions. J. Pharmacol. Exp. Ther. 311:14-21

Droby, S., Wisniewski, M., Macarisin, D. and Wilson, C. 2009. Twenty years of postharvest biocontrol research: Is it time for a new paradigm? Postharvest Biol. Technol. 52:137-145.

Eckert. J. W. and Ogawa, J. M. 1988. The chemical control of postharvest disease: deciduous fruits, berries, vegetables and root/tuber crops. Anmu. Rev. Phytopathol. 26:433-469.

Felsenstein, J. 1985. Confidence limits on phylogenies: An approach using the bootstrap. Evolution 39:783-791.

Hong, E.-J., Na, K.-J., Choi, I.-G, Choi, K.-C. and Jeung, E.-B. 2004. Antibacterial and antifungal effects of essential oils from coniferous trees. Biol. Pharm. Bull. 27:863-866.

Janisiewicz, W. J. and Korsten, L. 2002. Biological control of postharvest diseases of fruits. Annu. Rev. Phytopathol. 40:411441.

Jones, A. L. and Aldwinckle, H. S. 1991. Compendium of apple and pear diseases. The American Phytopathological Society, St. Paul, MN. USA.

Kimura, M. 1980. A simple method for estimating evolutionary rate of base substitution through comparative studies of nucleotide sequence. J. Mol. Evol. 16:111-120.

Kordali, S., Cakir, A., Mavi, A., Kilic, H. and Yildirim, A. 2005. Screening of chemical composition and antifungal and antioxidant activities of the essential oils from three Turkish Artemisia species. J. Agric. Food Chem. 53:1408-1416.

Lee, S. O., Kim, H. Y., Choi, G. J., Lee, H. B., Jang, K. S., Choi, Y. H. and Kim, J.-C. 2009. Mycofumigation with Oxyporus latemarginatus EF069 for control of postharvest apple decay and Rhizoctonia root rot on moth orchid. J. Appl. Microbiol. 106:1213-1219.

Li, X., Wang, G., Zhao, J., Ding, H., Cunningham, C., Chen, F., Flynn, D. C., Reed, E. and Li, Q. Q. 2005. Antiproliferative effect of beta-elemene in chemoresistant ovarian carcinoma cells is mediated through arrest of the cell cycle at the G2-M phase. Cell Mol. Life Sc. 62:894-904.
Malele, R. S., Mutayabarwa, C. K., Mwangi, J. W., Thoithi, G N. and Lopez, A. G 2003. Essential oil of Hyptis suaveolens (L.) Poit. from Tanzania: Composition and antifungal activity. $J$. Essential Oil Res. 15:438-440.

Ostlind, D. A., Felcetto T., Misura A., Ondeyka, J., Smith, S., Goetz, M., Shoop W. and Mickle, W. 1997. Discovery of a novel indole diterpene using first instars of Lucilia sericata. J. Med. Veterin. Entomol. 11:407-408.

Raines, D. E., Gioia, F., Claycomb, R. J. and Stevens, R. J. 2004. The $N$-methyl-D-aspartate receptor inhibitory potencies of aromatic inhaled drugs of abuse: evidence for modulation by cation- $\pi$ interactions. J. Pharmacol. Exp. Ther. 311:14-21.

Park, M. S., Seo, G. S., Bae, K. S. and Yu, S. H. 2005. Characterization of Trichoderma spp. associated with green mold of oyster mushroom by PCR-RFLP and sequence analysis of ITS regions of rDNA. Plant Pathol. J. 21:229-236.

Suto, M., Takebayashi, M., Saito, K., Tanaka, M., Yokota, A. and Tomita, F. 2002. Endophytes as producers of xylanase. J. Biosci. Bioeng. 93:88-90.

Stinson, A. M., Zidack, N. K., Strobel, G A., Jacobsen, B. J., 2003a. Mycofumigation Muscodor albus and Muscodor roseus for control of seedling diseases of sugar beet and Verticillium wilt of eggplant. Plant Dis. 87:1349-1354.

Stinson, A. M., Ezra, D., Hess, W. M., Sears, J. and Strobel, G 2003b. An endophytic Gliocladium sp. of Eucryphia cordifolia producing selective volatile antimicrobial compounds. Plant Sci. 165:913-922.

Strobel, G. A., Dirksie, J., Sears, J. and Markworth, C. 2001. Volatile antimicrobials from a novel endophytic fungus. Microbiol. 147:2943-2950.

Thompson, J. D., Gibson, T. J., Plewniak, F., Jeanmougin F. and Higgins, D. G 1997. The Clustal X windows interface: flexible strategies for multiple sequence alignment aided by quality analysis tools. Nucleic Acids Res. 24:4876-4882.

Wang, G., Li, X., Huang, F., Zhao, J., Ding, H., Cunnungham, C., Coad, J.E., Flynn, D. C., Reed, E. and Li, Q. Q. 2005. Antitumor effect of beta-elemene in non-small-cell lung cancer cells is mediated via induction of cell cycle arrest and apoptotic cell death. Cell Mol. Life Sci. 62:881-893.

Whalley A. J. S. 1996. The Xylariaceous way of life. Mycol. Res. 100:897-922.

Wilson, C. L. and Wisniewski, M. E. 1989. Biological control of postharvest diseases of fruits and vegetables an emerging technology. Anmu. Rev. Phytopathol. 27:425-441.

Wilson, C. L. and Wisniewski, M. E. 1994. Biological control of postharvest diseases: Theory and practice. CRC press, Fl, USA.

Yao, Y. Q., Ding, X., Jia, Y. C., Hunag, C. X., Wang, Y. Z. and Xu, Y.H. 2008. Anti-tumor effect of beta-elemene in glioblastoma cells depends on p38 MAPK activation. Cancer Lett. 264:127134.

Zhou, T., Chu, C., Liu, W. and Schaneider, K. 2001. Postharvest control of blue mold and gray mold on apples using isolates of Pseudomonas syringae. Can. J. Plant Pathol. 23:246-252. 